\title{
A Aprendizagem Experiencial no Curso de Administração Pública PNAP/EaD: Análise do Laboratório Aplicado de Administração Municipal (LAAM)
}

\author{
Experiential Learning in Public Administration \\ Course PNAP/DL: Analysis Applied Laboratory \\ in Municipal Administration
}

1 Júlio Cesar Andrade de Abreu*,

${ }^{2}$ Marcos Tanure Sanabio,

${ }^{2}$ Ricardo Rodrigues Silveira de Mendonça

1 Universidade Federal Fluminense. Rua Desembargador Ellis Hermydio Figueira, 783, Bairro Aterrado

Volta Redonda, RJ, Brasil.

*julioandrade@id.uff.br

2 Universidade Federal de Juiz de Fora - UFJF - Rua José Lourenço Kelmer, s/n São Pedro, Juiz de Fora - MG, Brasil.

\section{Resumo}

Este trabalho tem como objetivo discutir a implantação do Laboratório Aplicado de Administração Municipal (LAAM) no âmbito dos cursos vinculados ao Programa Nacional de Formação em Administração Pública (PNAP), pertencente ao Sistema UAB/Capes, bem como sua fundamentação teórica. Justifica-se tal iniciativa pela necessidade da utilização de práticas didático-pedagógicas com intensiva utilização de tecnologias da informação e comunicação (TIC) na modalidade EaD. Para tanto, este artigo tece uma breve discussão acerca da evolução do ensino a distância no País e da utilização das TIC na gestão pública. Como base teórica, é empregada a Teoria da Aprendizagem Experiencial de Kolb. Por fim, procura-se caracterizar o LAAM e a sua aplicabilidade na condução das ações de EaD. Conclui-se que a implantação do LAAM, valendo-se das bases teóricas kolbianas, poderá apresentar instigante potencial de melhoria da formação dos gestores públicos, uma vez que os diferentes estilos de aprendizagem estarão presentes nas diferentes etapas de funcionamento do LAAM

Palavras-chave: Aprendizagem Experiencial. Administração Pública. PNAP. LAAM. 


\section{Experiential Learning in Public Administration Course PNAPIDL: Analysis Applied Laboratory in Municipal Administration}

\section{Abstract}

This paper discusses questions about the Laboratório Aplicado de Administração Municipal (LAAM) in the context of courses associated to the Programa Nacional de Formação em Administração Pública (PNAP/UAB/Capes). This work can be justified by the need to use didactic and pedagogic practices with intensive use of information and communication technologies (ICTS) in distance education mode. Therefore, we herein discuss the evolution of distance education in Brazil and the use of ICT in Public Management. As a theoretical basis, we have employed Kolb's Experiential Learning Theory. Finally, LAAM and its applicability in conducting distance education activities is properly put into perspective. It is concluded that the implementation of the LAAM, based on the Kolb's theoretical framework, may present a potential for improving the training of public managers, since the different learning styles will be present in the different stages of operation of the LAAM.

Keywords: Experiential learning. Public Administration. PNAP. LAAM.

\section{Introdução}

A internet, que foi desenvolvida para a guerra, democratizada por hackers e absorvida pelo mercado, carrega em si grande potencial de fortalecimento democrático (SAMPAIO, 2010). Percebe-se que a internet pode ser colocada como um marco civilizatório: a vida antes e depois da internet, pois ela tem criado expectativas elevadas de mudanças, algumas até revolucionárias (PINHO, 2011). A própria morfologia das sociedades se modifica, assumindo a forma de uma organização social em rede; com isso, tudo se modifica - da experiência e da cultura ao poder e ao processo produtivo (NOGUEIRA, 2003).

Existe um crescente interesse, na academia e na prática governamental, por novas formas de relacionamento entre o Estado e a sociedade via internet, principalmente no que tange aos processos de tomada de decisão pública (CUNHA; POZZENON, 2009). Nesse sentido, o presente trabalho foca-se no emprego das tecnologias da informação e comunicação (TIC) no processo de aprendizagem em um curso de bacharelado em Administração Pública na modalidade EaD. Dado o papel relevante da formação de futuros gestores públicos e da qualificação de quadros atuais de servidores públicos, a escolha por esse curso como objeto de análise do presente artigo mostra-se providencial.

O processo de aprendizagem foi objeto de estudo de vários pesquisadores. Ausubel (1982) e Batista e Silva (2010), por exemplo, entendem que o processo de aprendizagem e fixação de conhecimentos toma como base aspectos emocionais individuais. Isso afasta do debate e ao mesmo tempo critica o chamado modelo de aprendizagem "mecânica".

De acordo com Ausubel (1982), a aprendizagem torna-se significativa quando os novos conteúdos transmitidos são incorporados às estruturas de conhecimentos prévios dos alunos. Para Kolb (1984), o conhecimento é gerado num processo contínuo em que as experiências concretas servem de base para a observação, a reflexão e a aprendizagem. Seria essa a ideia da Teoria da Aprendizagem Experiencial de Kolb (1984). 
É nesse cenário, em que a sociedade da informação e as TIC moldam os processos de ensino, principalmente na modalidade EaD, que se busca compreender como a aprendizagem experiencial pode ser aplicada ao bacharelado em Administração Pública do Programa Nacional de Formação em Administração Pública (PNAP), pertencente ao Sistema UAB/Capes.

Este artigo tem como objetivo discutir a implantação do Laboratório Aplicado de Administração Municipal (LAAM) no âmbito do PNAP e sua fundamentação teórica. E está estruturado do seguinte modo: além desta introdução, é desenvolvido um tópico sobre a Educação a Distância no Brasil e suas interfaces com as TICs; em seguida, é apresentado o histórico do programa PNAP e suas características para formação de administradores públicos; no tópico seguinte, o foco é direcionado para os processos de aprendizagem, em especial a Teoria da Aprendizagem Experiencial. Em seguida, o trabalho se dedica ao debate e à reflexão sobre a aplicabilidade da aprendizagem experiencial no ensino de conteúdos sobre "governo eletrônico" num curso de Administração Pública na modalidade EaD. Finalmente, são tecidas conclusões deste estudo.

\section{Educação a Distância (EaD): breves considerações}

A Educação a Distância (EaD) surgiu no cenário educacional nacional e internacional como uma modalidade de aprendizagem extremamente adequada às novas demandas das sociedades contemporâneas (BELLONI, 2008). Tal fato pode ser comprovado pelo Anuário Brasileiro Estatístico de Educação Aberta e a Distância, que apresenta dados consistentes sobre o aumento do volume de matrícula em cursos na modalidade EaD (ABED, 2016).

O Censo EAD.BR 2016 contabilizou 561.667 alunos em cursos regulares totalmente a distância, 217.175 em cursos regulamentados semipresenciais, 1.675.131 em cursos livres não corporativos e 1.280.914 em cursos livres corporativos. Os números são expressivos e revelam o potencial da EaD para atender a demandas regulamentadas de educação e, mais ainda, demandas de formação continuada (ABED, 2016, p. 79).

A distribuição detalhada desses estudantes pode ser observada no gráfico da Figura 1.

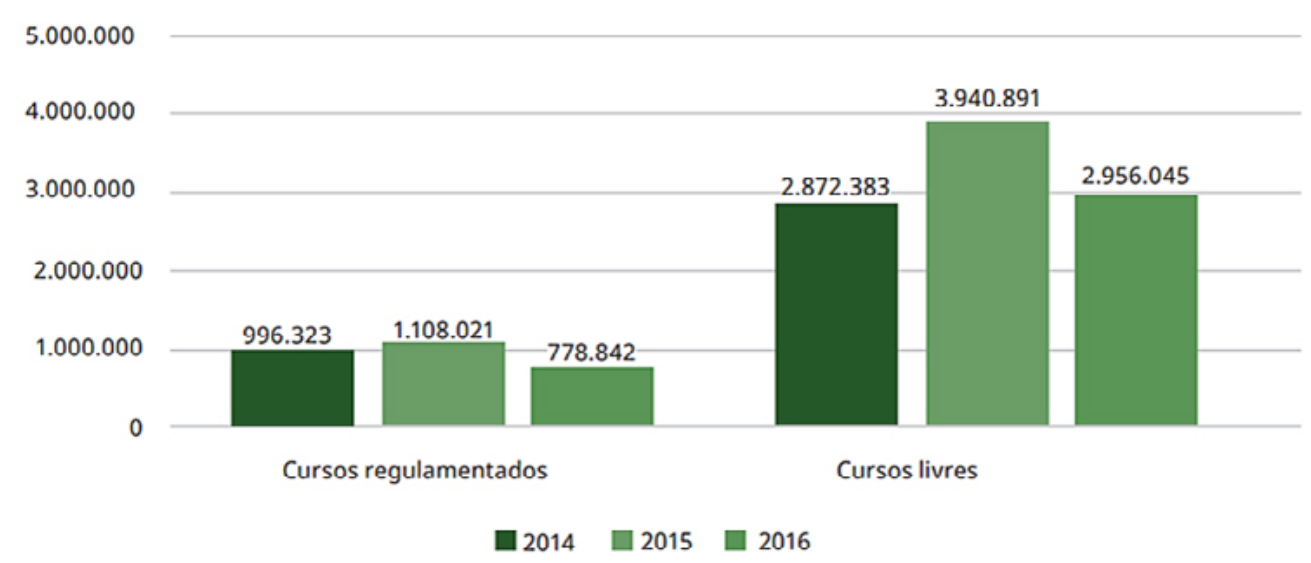

Figura 1: Quantidade de alunos matriculados em cursos regulamentados e livres Fonte: $\operatorname{ABED}(2016$, p. 80).

A Educação a Distância ou educação online pode ser definida como "o processo de ensino-aprendizagem, mediado por tecnologias, em que professores e alunos estão separados espacial e/ou temporal- 
mente" (MORAN, 1994, p. 2). Reforçando tal argumento, alguns autores afirmam que o conceito de educação online vincula-se ao fenômeno da cibercultura (CAMPOS; COSTA; SANTOS, 2007). Percebe-se então o uso decisivo e central das TIC na Educação a Distância. O processo educacional é complexo e demanda tecnologias para as ações de interação entre os docentes e alunos (BELLONI, 2008). Essa autora pondera ainda que o quadro-negro ou o livro são ferramentas tecnológicas para tal interação. Porém, para ela, a EaD necessita de tecnologias e processos de comunicação que possam, por exemplo, promover a interação entre docentes e aprendizes dentro de contextos de espaço (a distância) e tempo (síncronos e assíncronos) distintos.

O uso intensivo das TIC no cenário atual da EaD possibilita assumir um contorno ferramental que visa fortalecer a socialização das informações a partir de diversos dispositivos, tais como: redes de conferências; ambientes de aprendizagem online; videoaulas; wikis; blogs; webconferências; avatares; dispositivos móveis e celulares, entre outros (BRUNO; LEMGRUBER, 2010). A evolução das TIC em cursos de EaD demonstra a migração de tecnologias de geração textual (livros, apostilas, artigos) para uma geração analógica que envolve mídias (tais como televisão, vídeo e rádio) e atualmente para uma nova geração com perfil digital, caracterizada pela adoção de ferramentas eletrônicas, com destaque para o elenco composto por hipertextos, multimídias, softwares educacionais, realidade virtual, simuladores e jogos (CAMPOS et al., 2007).

\section{PNAP: origens, concepção e estrutura curricular}

A partir da década de 1990, a questão da gestão pública nacional vem passando por profundas transformações, especificamente na redistribuição do papel das três esferas de governo. A Constituição de 1988 determina que estados e municípios assumam atividades anteriormente desempenhadas pela União. Nesse sentido, estes dois níveis de governo convivem com atributos complexos e que demandam competência e capacitação dos seus quadros funcionais (SILVA et al., 2008).

Em 2006 foi desenvolvido um curso de graduação em Administração na modalidade EaD para servidores do Banco do Brasil. Tal iniciativa (chamada de "projeto piloto") se mostrou bem-sucedida sendo posteriormente a base para o Programa Nacional de Formação em Administração Pública - PNAP (MATIAS-PEREIRA et al., 2007).

Historicamente, a ideia original envolvia, além do bacharelado em Administração Pública, quatro especializações e um mestrado profissional. Na formatação da versão final, a especialização em Gestão da Educação Pública foi retirada do projeto (uma vez que existia o interesse de desenvolvimento desse curso por setores ligados ao curso de Pedagogia, no âmbito do MEC), bem como o curso de mestrado profissional.

Em sua versão definitiva, o PNAP é composto por três especializações (Gestão Pública, Gestão Municipal e Gestão da Saúde Pública) e um bacharelado. A lógica posta no PNAP é de verticalização do processo de formação, ou seja, após ingressar no bacharelado, o estudante deverá selecionar uma linha de formação específica (LFE) para realizar seu trabalho de conclusão de curso (TCC) entre as três LFE existentes (Gestão da Saúde Pública, Gestão Municipal e Gestão Governamental). A definição dessas linhas no projeto pedagógico do curso considerou a demanda nacional por profissionais formados com conhecimentos nas áreas das LFE. As especializações lato sensu do PNAP estão diretamente ligadas às LFE, de modo que se constituem em um aprofundamento dos estudos realizados no bacharelado. Por fim, o mestrado profissional em Administração Pública faria uma formação em pesquisa aplicada e avançada (POLL; ABREU, 2010). Deve-se destacar que o mestrado profissional foi concebido e implementado vários anos após a consolidação do PNAP.

1 Para mais detalhes ver http://www.profiap.org.br/profiap/sobre-o-curso/sobre-o-curso 


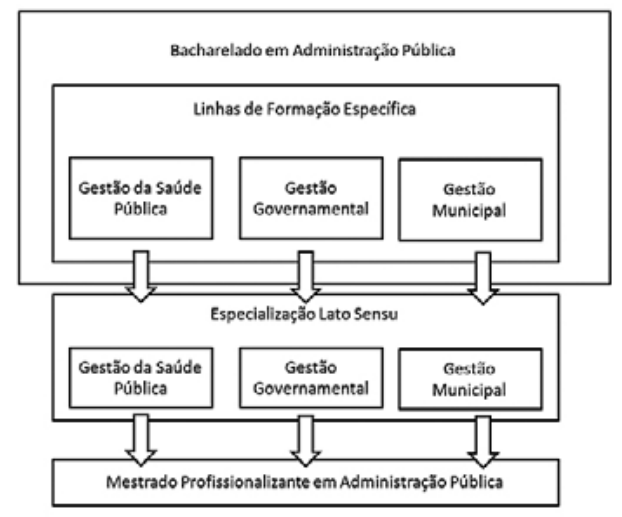

Figura 2: Verticalização do PNAP

A concepção do curso de bacharelado em Administração Pública está voltada para a formação de egressos capazes de atuar de forma eficiente e eficaz no contexto da gestão pública, à luz da ética, buscando contribuir para o alcance dos objetivos e desenvolvimento das organizações governamentais e não governamentais, de forma a viabilizar o atendimento às necessidades e ao desenvolvimento da sociedade brasileira ${ }^{2}$.

Para tal, o curso contempla sólida formação nas teorias administrativas e enfatiza o desenvolvimento de competências necessárias ao bom desempenho profissional do gestor público, além de formação generalista, permitindo assim definir um perfil de administrador público moderno, capacitado a planejar, organizar, dirigir e controlar a ação e as políticas públicas nas diversas esferas de poder e de governo.

O projeto pedagógico do curso procura valorizar, assim, a formação de atitudes de reflexão, de busca de inovações, de prospecção e criação de caminhos próprios que possam suprir as necessidades da gestão pública e permitir a atuação nos processos operacionais e decisórios sob a égide do conhecimento, da ética, da cidadania e da humanidade.

A estrutura curricular do curso contempla disciplinas cujos conteúdos revelam as inter-relações das dimensões da realidade público-privada, nacional-internacional, assim como das esferas federal, estadual e municipal, numa perspectiva histórica e contextualizada de sua aplicabilidade, no âmbito das organizações e do meio, utilizando tecnologias inovadoras e atendendo aos demais campos interligados de formação, conforme especificado nas Diretrizes Curriculares Nacionais (DCN) para os cursos de Administração.

Sendo o foco deste trabalho, o bacharelado em Administração Pública na modalidade EaD tem se apresentado muito diversificado em termos de perfis de alunos (SIMÃO; ABREU; EVARISTO, 2014). Nesse sentido, é adequado propor que projetos de ensino busquem considerar tal diversidade em suas concepções, como é o caso do Laboratório Aplicado de Administração Municipal, que será explicitado nos próximos tópicos.

\section{A Teoria da Aprendizagem Experiencial de Kolb}

Após muitos anos de pesquisa, David Kolb, inspirado nos trabalhos de Vygotsky, publicou em 1984 seu estudo sobre modelos de aprendizagem. Esse trabalho forneceu aos pesquisadores importante subsídio para compreensão e explicação do comportamento de aprendizagem humana. O homem é capaz de aprender a partir de suas experiências (BATISTA; SILVA, 2010). Esse modelo foi denominado Aprendizagem

2 Este tópico tem como principal fonte bibliográfica o projeto pedagógico do curso de bacharelado em Administração Pública do PNAP 
Experiencial. Por estar inserido em um contexto cultural e mesmo integrado ao meio natural, o ser humano, no entendimento de Kolb, pode se empenhar para buscar o aprendizado de algo que lhe faça sentido dentro de vivências já realizadas. A obra de Kolb destaca as várias possibilidades de aplicação da análise e dos estilos de aprendizagem para a área acadêmica (TREVELIN, 2011).

Deve-se destacar que "todo desenvolvimento profissional prospectivo decorre da aprendizagem atual, assim como o desenvolvimento já constituído é imprescindível para o aprendizado" (PIMENTEL, 2007, p. 160); essa é a premissa da Aprendizagem Experiencial. Entretanto, isso não significa que qualquer experiência resulte em aprendizado.

Dentro dessa perspectiva, a aprendizagem passa a ser vislumbrada como um processo social. A interação entre os conhecimentos prévios, a trajetória e as circunstâncias do ambiente externo ganha ênfase na abordagem da Aprendizagem Experiencial. Para Kolb (1984, p. 133),

o processo de aprendizagem advindo da experiência determina e atualiza o desenvolvimento potencial. Essa aprendizagem é um processo social; portanto, o curso de desenvolvimento individual é determinado pelo sistema cultural e social de conhecimento.

A teoria kolbiana salienta quatro tipos de estilos de aprendizagem, os quais são baseados em um círculo de aprendizagem de quatro estágios. De modo geral, esse círculo indica que experiências concretas fornecem uma base para que reflexões e observações sejam realizadas. Uma vez realizadas, essas reflexões subsidiam a construção de conceitos abstratos; estes, por sua vez, geram novas implicações para as ações que podem ser ativamente testadas e criam novas experiências (KOLB, 1984). Esse processo "representa um círculo de aprendizagem ou espiral em que o aprendiz 'toca todas as bases', isto é, um círculo de experiência, reflexão, pensamento e atividade" (BATISTA; SILVA, 2010, p. 3). Experiências concretas ou imediatas conduzem a observações e reflexões. Essas reflexões são então assimiladas (absorvidas e traduzidas) em conceitos abstratos com implicações para a ação que a pessoa pode ativamente testar e com as quais experimentar, o que, por sua vez, habilita à criação de novas experiências.

O modelo de Kolb apresenta então um círculo de quatro estágios: (1) Experiência Concreta; (2) Observação Reflexiva; (3) Conceituação Abstrata; e (4) Experimentação Ativa. A figura a seguir demonstra a articulação do Ciclo de Aprendizagem de Kolb.

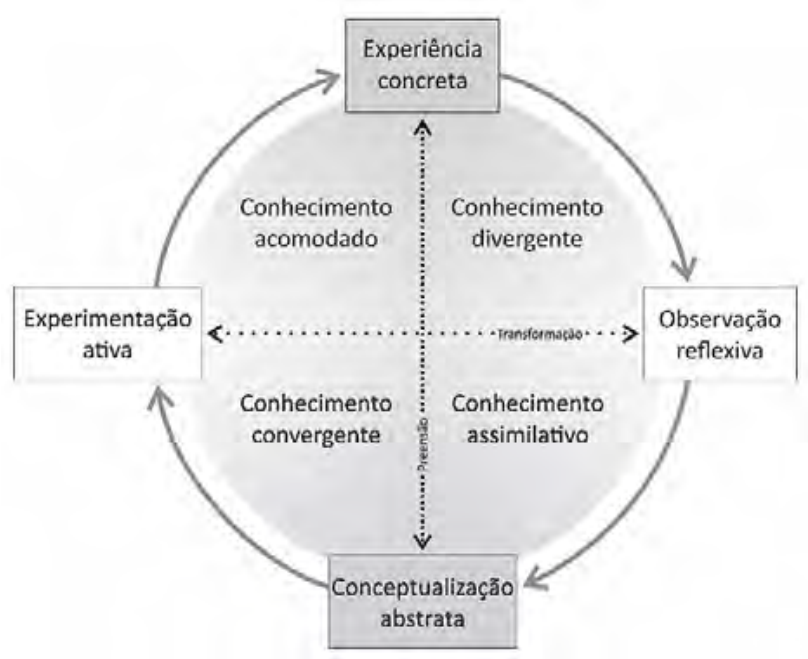

Figura 3: Ciclo de Aprendizagem de Kolb

Fonte: Kolb (1987). 
De modo geral, os estágios podem ser descritos do seguinte modo (KOLB, 1984; PIMENTEL, 2007): a Experiência Concreta $(E C)$ refere-se ao contato direto com experiências e situações que trazem problemas a serem solucionados. Ações e processos mentais anteriores servem como matéria-prima para aprendizados ulteriores. A Observação Reflexiva (OR) refere-se ao olhar interior, à reflexão e meditação sobre situações vivenciadas. Caracteriza-se pela identificação de elementos, associações e agrupamentos entre fatos. A Conceituação Abstrata (CA) refere-se à comparação entre realidades semelhantes e à formação de conceitos e abstração generalizáveis para outros elementos da experiência. Caracteriza-se pelo estabelecimento de sínteses e trocas de opiniões em que um eixo comum de ideias é estabelecido. A Experiência Ativa (EA) é um movimento externo da ação. Trata-se da repercussão da aprendizagem, gerando experiências inéditas. Caracteriza-se pela aplicação prática dos conhecimentos e processos assimilados.

A Experiência Ativa utilizada no âmbito do LAAM apresenta aderência, além do modelo de Kolb, com o chamado Arco de Maguerez. Deve-se destacar que

o Arco de Charles Maguerez (...) é uma das estratégias de ensino-aprendizagem para o desenvolvimento da problematização. Consta de cinco etapas que acontecem a partir da realidade social: a observação da realidade, os pontos-chave, a teorização, as hipóteses de solução e aplicação à realidade (PRADO; VELHO; ESPÍNDOLA; SOBRINHO; BACKES, 2012, p. 174).

As etapas do Arco de Maguerez podem ser observadas na figura a seguir.

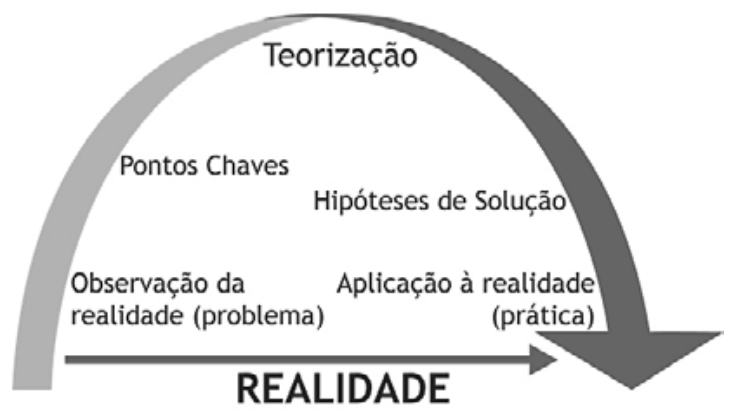

Figura 4: Arco de Maguerez

Fonte: Baseado em Prado (2012, p. 176) e Borrile (2012).

Nesse sentido, tanto o ciclo de Kolb como o Arco de Maguerez se aplicam às diferentes etapas de operação do LAAM, como será detalhado no tópico a seguir, sempre com o objetivo de realizar uma experiência de aprendizagem ativa.

\section{Aplicação da Aprendizagem Experiencial no ensino em Administração Pública: a Proposição do LAAM}

Os desafios impostos para projetos de Educação a Distância, no que tange à dinâmica da aprendizagem, são constantes. Nesse cenário, a reflexão sobre alternativas mais efetivas de ensino e que tivessem condições de postular uma aprendizagem experiencial conduziram ao desenvolvimento de um Laboratório Aplicado de Administração Municipal (LAAM).

O LAAM é operacionalizado a partir do software e-Cidade, do Programa Software Público, do Ministério do Planejamento, Orçamento e Gestão (MPOG). Percebendo o grande potencial de melhoria da gestão 
pública, via instrumentos de e-Gov, o MPOG organizou um sítio que agrega diversos programas livres para uso em organizações públicas, criando comunidades de debate entre desenvolvedores, usuários, acadêmicos e gestores. A ideia do software púbico fundamenta-se em

software desenvolvido pelo setor público como objeto de compartilhamento; pode ser obtido na Teoria dos Bens Públicos: bem público como aquele que apresenta características de indivisibilidade e de não rivalidade (PETERLE; DE CASTRO; MEFFE; BRETAS; SANTOS, 2005, p. 1).

O software, entendido como bem público, pode ser utilizado por diversas organizações públicas para aprimoramento da gestão. Em especial, o programa e-Cidade, desenvolvido pela empresa DBSeller e registrado como software livre, tem tido grande aceitação em várias gestões municipais. Por esse motivo, o programa foi selecionado como base para operacionalização do LAAM.

O e-Cidade é um ERP (Enterprise Resource Planning - sistema integrado de gestão empresarial) ${ }^{3}$ com diversos módulos integrados, capaz de informatizar os diversos setores de uma prefeitura ou ser implantado em módulos separados, de acordo com a necessidade da gestão municipal.

Em termos de plataforma tecnológica, o e-Cidade faz uso do Apache 2 e do PHP 5; como SGBD (sistema de gerenciamento de banco de dados), usa o PostgresSQL 8.2, rodando em um sistema operacional Linux.

Nesse cenário, o LAAM funcionaria como um integrador de ambientes virtuais, viabilizando o processo de aprendizagem experiencial dos alunos pelo uso do e-Cidade. O ciclo de Kolb (1987) carrega em si quatro grandes fases: o aplicar, o agir, o refletir e o conceitualizar. Isso posto, destaca-se que a ideia central é que o LAAM seja de fato um laboratório, ou seja, um ambiente para realização de experiências de gestão municipal, favorecendo o processo de aprendizagem dos alunos sob um paradigma da teoria kolbiana.

A operação do LAAM se daria do seguinte modo: com base no ciclo de aprendizagem, a dinâmica do LAAM pode ser dividida em quatro momentos - Aplicação, Ação, Reflexão e Contextualização - e em três ambientes - Ambiente Simulado de Capacitação (ASC), Ambiente Digital do e-Cidade (ADeC) e Ambiente Virtual de Aprendizagem (AVA). Obviamente, o aluno deve passar por uma capacitação para o uso do e-Cidade. Isso ocorrerá por meio de um ASC com tutoriais autoexplicativos, de modo que os alunos irão vivenciar uma "experiência concreta", testando e conhecendo o e-Cidade. Após conhecerem o e-Cidade no ASC, os alunos utilizarão o AVA, onde terão acesso a um banco de dados contextualizado (BDC) oriundo de uma prefeitura virtual. Esse será um momento de observação e reflexão, em que ele se questionará sobre como utilizar tais dados no e-Cidade. Em seguida, o aluno irá se dirigir para o ADeC onde os dados da prefeitura virtual e do BDC serão lançados e processados. Após o lançamento dos dados, os alunos irão gerar relatórios e gráficos e usar a ferramenta de business intelligence (BI) do e-Cidade. Nesse momento, eles estarão vivenciando um processo de conceitualização em que os diferentes achados da relação teoria x prática e reflexão x aplicação irão emergir. Finalmente, com esses achados, os alunos irão retornar ao AVA para debater seus achados e resultados com tutores, professores e outros alunos. Isso irá gerar uma experimentação ativa e mesmo uma revisão da teoria estudada.

3 ERP são sistemas integrados, em que todas as funcionalidades (ou módulos) estão disponíveis para uso (por exemplo: módulo financeiro, de gestão de pessoas, orçamentário, entre outros). Para mais detalhes, acessar: https://softwarepublico.gov.br/ social/e-cidade 
A metodologia do LAAM, baseada no ciclo de Kolb, pode ser visualizada de modo processual na Figura 5.

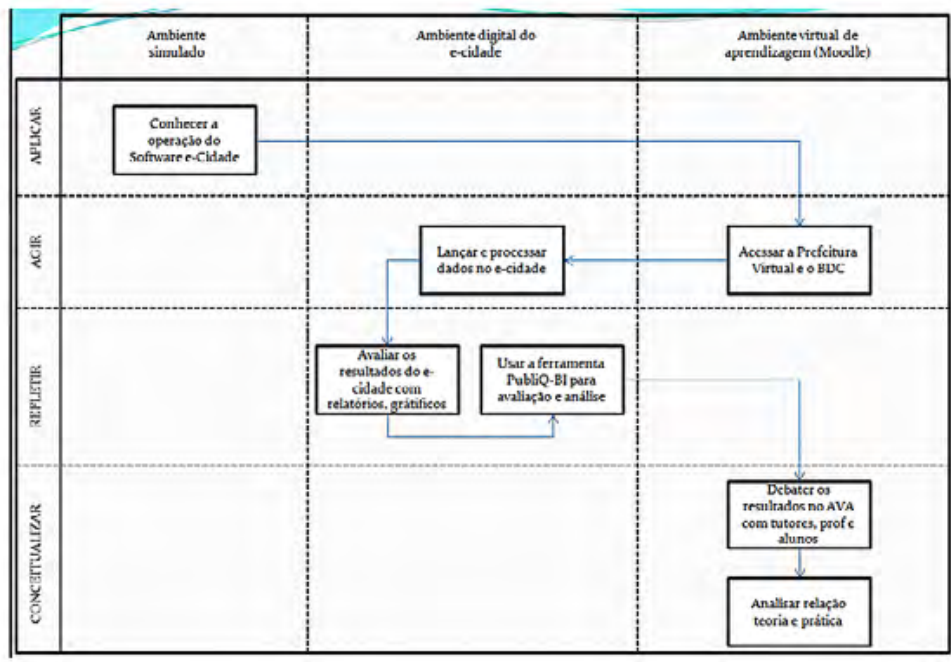

Figura 5: Aplicação do LAAM

Cabe destacar que essas etapas também apresentam relação com o Arco de Maguerez, uma vez que as ações ali estabelecidas partem de uma problemática para aplicação e resolução prática.

Entende-se, assim, que o Laboratório Aplicado de Administração Municipal - LAAM tende a ser um "espaço virtual" de interação entre docentes, tutores e estudantes do PNAP, permitindo ainda a extensão do acesso aos cursos presenciais.

É oportuno mencionar que a busca por equalizar o binômio que enlaça teoria x prática pode ser considerada um dos fatores determinantes para os cursos de formação em Administração, tanto na graduação quanto na pós-graduação. Assim se pode entender que, de modo até certo ponto recorrente, os alunos apresentam demandas por uma maior praticidade nas ações educacionais, em contraponto às práticas de verbalização normalmente adotadas nas instituições de ensino superior (IES), na medida em que são suportadas e transmitidas com o forte apoio e emprego discussões teóricas, cuja contextualização muitas vezes só pode ser obtida por intermédio do acesso do aluno ao espaço laboral das organizações.

De modo ainda mais específico, para contornar essa situação, nos cursos de formação em Administração o corpo docente tem por métrica formatar instrumentos didático-pedagógicos como a adoção de estudos de casos; exercícios e trabalhos de campo e jogos organizacionais. Contudo, mesmo reconhecendo a validade de tais instrumentos de ensino, eles ficam restritos às ilustrações de como os conceitos, as teorias e os modelos podem ser aplicados e de como essa ação pode elucidá-los sobre como agir em determinadas situações. Nesse aspecto em particular, entre as alternativas para aproximar os modelos teóricos das práticas de gestão, deve ser considerada a possibilidade da criação de Laboratórios Acadêmicos para os Cursos de Administração, entendidos aqui como salas ou espaços físicos equipados com softwares para realização de experiências, simulações e análises de situações objetivas e reais envolvendo eventos recorrentes no cotidiano das organizações públicas e privadas e daquelas vinculadas ao terceiro setor.

Tal alternativa sinaliza, portanto, uma proposta inovadora no processo de ensino, aprendizagem e experimentação de atividades que podem envolver de forma coordenada a elaboração experimental de projetos, bens e serviços relativos ao desenvolvimento e aprimoramento dos alunos vinculados aos programas das disciplinas que compõem a estrutura curricular, principalmente no que tange à formação do administrador público. 
Estima-se, por fim, que tais espaços de aprendizagem, por suas características e importância, podem contribuir de forma significativa para dinamizar os processos de ensino, pesquisa e extensão, principalmente pela perspectiva do envolvimento maciço da comunidade acadêmica (docentes, discentes e profissionais técnico-administrativos) e de outras organizações públicas e privadas.

\section{Conclusões}

Atualmente, vivencia-se um período histórico que pode ser considerado turbulento e em fase de constante transição; os modelos e paradigmas tradicionais de compreensão e explicação da realidade estão sendo revistos, enquanto outros estão emergindo. Nesse cenário de profundas transformações, as teorias clássicas no campo da Educação e da Administração parecem não responder de forma tão imediata à complexidade dos fenômenos contemporâneos e, especificamente, das práticas no campo dos processos de ensinar e de aprender sobre Administração Pública; nesse aspecto em particular, infere-se que a chamada abordagem positivista precisa ser atenuada, ainda que gradualmente. Os atuais paradigmas educacionais trazem à tona a necessidade da participação, da construção do conhecimento, da autonomia de aprendizagem, da adoção do currículo aberto, das redes de conhecimentos, da interconectividade dos problemas e dos espaços de relações. No campo da Administração valorizam-se conceitos como pró -atividade; empowerment; fidelização; gestão do conhecimento; ética e responsabilidade socioambiental; governança corporativa; inovação tecnológica; transparência nos processos de gestão público-privada; inclusão social; e a ideia de "Estado necessário", entre outros.

A EaD, nesse sentido, pode então oferecer possibilidades de novas práticas educativas e sociais, por suas características e sua forma de organizar o ensino e a aprendizagem voltados aos processos formativos profissionais, encarados aqui em sentido amplo. Para tal, exige uma estreita associação entre a organização de apoio institucional e a mediação pedagógica que garanta as condições necessárias à efetivação do ato educativo. É possível afirmar então que, na modalidade a distância, quem ensina não é necessariamente um professor, mas uma instituição, uma "instituição ensinante". Trata-se, então, de uma ação mais complexa e coletiva, na qual todos os sujeitos do processo de ensino-aprendizagem estão envolvidos direta ou indiretamente: a equipe que concebeu e construiu o projeto pedagógico, composta por sujeitos ativos na implementação de tal projeto; aqueles que irão conceber e elaborar o material didático; aqueles que cuidarão para que ele chegue às mãos do estudante, do coordenador de curso e dos professores, encarados aqui na condição de formadores, ao orientador (tutor), do autor ao tecnólogo educacional (instrucional designer), do editor ao artista gráfico (webdesigner) etc.

Por isso, a modalidade EaD deve ser pensada e implementada pela "instituição ensinante" numa perspectiva sistêmica e colaborativa. A metáfora da rede traduz bem essa nova visão da organização do trabalho pedagógico; é nesse aspecto em particular que a proposta de criação do LAAM pode projetar para patamares superiores o espaço de atuação dos estudantes do PNAP, contribuindo assim para oferecer um ambiente educacional confeccionado com qualidade e permeado por um campo permanente de troca envolvendo experiências e vivências capazes de estimular ainda mais a formação de gestores públicos realmente comprometidos com as grandes questões nacionais, sem que para tanto tenham que abdicar das percepções sobre aspectos pontuais para as quais o correto exercício da gestão tende a oferecer soluções que podem ser construídas com talento, competência e criatividade, sem que para tanto, tenham que abdicar dos preceitos legais, éticos e regimentais que a profissão exige.

Assim, a abordagem colaborativa que esse processo sugere perpassa instintivamente a necessidade de adotar o laboratório (LAAM) como espaço de práticas contributivas e, mais do que isso, contextualizadas, com base no acesso e manuseio de dados reais que permeiam cotidianamente a gestão das organizações públicas; nessa linha de raciocínio incluem-se a execução de atividades pedagógicas que permitiriam, por exemplo, o exercício de múltiplas simulações e paralelamente a análise dos impactos advindos das 
decisões construídas, principalmente aquelas aplicadas à esfera de atuação no âmbito municipal. Concluise que a implantação do LAAM, valendo-se das bases teóricas kolbianas, poderá apresentar instigante potencial de melhoria da formação dos gestores públicos, uma vez que os diferentes estilos de aprendizagem estarão presentes nas diferentes etapas de funcionamento do LAAM.

\section{Agradecimentos}

Os autores agradecem o apoio da Faperj e do CNPq.

\section{Referências Bibliográficas}

ABED - ASSOCIAÇÃO BRASILEIRA DE EDUCAÇÃO A DISTÂNCIA. Relatório analítico da aprendizagem a distância no Brasil. Curitiba: InterSaberes, 2016.

AUSUBEL, D. P. A aprendizagem significativa: a teoria de David Ausubel. São Paulo: Moraes, 1982.

BATISTA, G. A.; SILVA, M. R. L. Estilos de Aprendizagem - Kolb. Fucamp, v. 1(1), 2010. Disponível em: http:// www.fucamp.edu.br/wp-content/uploads/2010/10/11a-GUSTAVO-E-MÁRCIA.pdf

BELLONI, M. L. Educação à distância. Campinas: Autores Associados, 2008.

BRUNO, A. R.; LEMGRUBER, M. S. Docência na Educação online: professorar e (ou) tutorar? In: BRUNO, L. S. P.; BORGES, Adriana Rocha; SILVA, Eliane Medeiros e (Ed.). Tem Professor n@ Rede. Juiz de Fora: Editora UFJF, 2010. p. 135.

CAMPOS, F. C. A.; COSTA, R. M. E.; SANTOS, N. Fundamentos da Educação a Distância, Mídias e Ambientes Virtuais (Cecierj). Rio de Janeiro: Fundação Cecierj/Consórcio Cederj, 2007.

CUNHA, M. A.; POZZEBON, M. O uso das tecnologias da informação e comunicação para melhoria da participação na tomada de decisão pública. In: Anais XXXIII EnANAPD - Encontro da Associação de Pós-Graduação em Administração (p. 15). São Paulo, 2009.

KOLB, D. Experiential Learning. New Jersey: Prentice Hall, 1984.

MATIAS-PEREIRA, J.; SANABIO, M. T.; MENDONÇA, R. R. S.; CASTANHA, A. L. B. Um estudo de caso do processo de institucionalização e gestão do Curso Piloto de Graduação em Administração da Universidade Aberta do Brasil - UAB/MEC. In: Anais XXXI EnANAPD, 2007.

MORAN, J. M. O que é educação à distância? Informe CEAD - Centro de Educação a Distância, v. 5(1), 1994.

NOGUEIRA, M. A. Organizações complexas e sociedade da informação: o sofrimento como metáfora organizacional. Organizações \& Sociedade, v. 10(28), p. 145-162, 2003. Disponível em: http://www.scielo. $\mathrm{br} / \mathrm{pdf} / \mathrm{osoc} / \mathrm{v} 10 \mathrm{n} 28 / 10 . \mathrm{pdf}$

PETERLE, A.; CASTRO, C. A. J. De; MEFFE, C.; BRETAS, N. L.; SANTOS, R. S. dos. Materialização do conceito de software público: iniciativa CACIC. Informática Pública, v. 7(2), p. 19-28, 2005. Disponível em: http:// www.ip.pbh.gov.br/ANO7 N2 PDF/IP7N2 peterle.pdf.

PIMENTEL, A. A teoria da aprendizagem experiencial como alicerce de estudos sobre desenvolvimento profissional. Estudos de Psicologia, Natal, v. 12(2), p. 159-168, 2007. https://doi.org/10.1590/S1413294X2007000200008. 
PINHO, J. A. G. de. Sociedade da informação, capitalismo e sociedade civil: reflexões sobre política, internet e democracia na realidade brasileira. Revista de Administração de Empresas, v. 51(1), p. 98-106, 2011. https://doi.org/10.1590/S0034-75902011000100009.

POLL, A. P.; ABREU, J. C. de. Curso de Administração Pública: alinhamento, dispersão ou formação de um novo campo? Temas de Administração Pública, 2010.

PRADO, M. L. Do; VELHO, M. B.; ESPÍNDOLA, D. S.; SOBRINHO, S. H.; BACKES, V. M. S. Arco de Charles Maguerez: refletindo estratégias de metodologia ativa na formação de profissionais de saúde. Escola Anna Nery, v. 16(1), p. 172-177, 2012. https://doi.org/10.1590/S1414-81452012000100023.

SAMPAIO, R. C. Internet como esfera pública? Cadernos PPG-AU/UFBA, p. 9(1), p. 87-104, 2010.

SILVA, M. A.; LIMA FILHO, D. O.; RIBEIRO, S.; CASTANHA, A. L. B.; SANABIO, M. T. Projeto pedagógico do Programa de Pós-graduação Lato Sensu em Administração Pública. Juiz de Fora: UFJF, 2008.

SIMÃO, A.; ABREU, J. C. A. de; EVARISTO, R. Sociedade da informação e educação a distância: conhecendo o perfil dos alunos do bacharelado em Administração Pública (EaD) da Universidade Federal Fluminense. EaD Em Foco, v. 4(2), 2014. https://doi.org/10.18264/eadf.v4i2.228.

TREVELIN, A. T. C. Estilos de aprendizagem de Kolb: estratégias para a melhoria do ensino-aprendizagem. Review of Learning Styles, v. 7(7), p. 1-16, 2011. 